\title{
Opiate Analgesics as Negative Modulators of Adult Hippocampal Neurogenesis: Potential Implications in Clinical Practice
}

\author{
Valeria Bortolotto and Mariagrazia Grilli* \\ Laboratory of Neuroplasticity, Department of Pharmaceutical Sciences, University of Piemonte Orientale, Novara, Italy
}

\section{OPEN ACCESS}

Edited by:

Maria Angela Sortino,

University of Catania, Italy

Reviewed by:

Cesare Patrone,

Karolinska Institutet, Sweden

Anna Maria Pittaluga,

University of Genoa, Italy

*Correspondence:

Mariagrazia Grill

mariagrazia.grill@uniupo.it

Specialty section:

This article was submitted to

Experimental Pharmacology and Drug

Discovery,

a section of the journal

Frontiers in Pharmacology

Received: 11 March 2017

Accepted: 24 April 2017

Published: 09 May 2017

Citation:

Bortolotto V and Grilli M (2017)

Opiate Analgesics as Negative

Modulators of Adult Hippocampal Neurogenesis: Potential Implications

in Clinical Practice.

Front. Pharmacol. 8:254.

doi: 10.3389/fphar.2017.00254
During the past decade, studies of the mechanisms and functional implications of adult hippocampal neurogenesis (ahNG) have significantly progressed. At present, it is proposed that adult born neurons may contribute to a variety of hippocampalrelated functions, including specific cognitive aspects and mood regulation. Several groups focussed on the factors that regulate proliferation and fate determination of adult neural stem/progenitor cells (NSC/NPC), including clinically relevant drugs. Opiates were the first drugs shown to negatively impact neurogenesis in the adult mammalian hippocampus. Since that initial report, a vast array of information has been collected on the effect of opiate drugs, by either modulating proliferation of stem/progenitor cells or interfering with differentiation, maturation and survival of adult born neurons. The goal of this review is to critically revise the present state of knowledge on the effect of opiate drugs on the different developmental stages of ahNG, as well as the possible underlying mechanisms. We will also highlight the potential impact of deregulated hippocampal neurogenesis on patients undergoing chronic opiate treatment. Finally, we will discuss the differences in the negative impact on ahNG among clinically relevant opiate drugs, an aspect that may be potentially taken into account to avoid long-term deregulation of neural plasticity and its associated functions in the clinical practice.

Keywords: opiates, morphine, methadone, tapentadol, neural stem cells, adult neurogenesis, chronic pain, depression

\section{ADULT NEUROGENESIS: RELEVANCE IN PHYSIOLOGY, PATHOLOGY, AND THERAPY}

Extensive experimental work demonstrated that new neurons can be generated in adult mammalian brain (Bergmann et al., 2015). One adult neurogenic area is the dentate gyrus, in the hippocampal formation. Here, in a subregion called the SubGranular Zone (SGZ), resident neural stem/progenitor cells (NSC/NPC) are present, can self-renew and give rise to transiently amplifying progenitor cells which, in turn, generate neuroblasts capable of terminal neuronal differentiation in the granular cell layer (Kempermann et al., 2003, 2004; Seri et al., 2004; Bonaguidi et al., 2012).

Recently a comprehensive review summarized data on how hippocampal function and related behavior may be modified by newborn neurons (Gonçalves et al., 2016). At present, adding new neurons in the hippocampal circuitry is suggested to result in encoding of temporal information into memories and in cognitive flexibility during new task learning. Pattern separation is the process that reduces overlap in the representation of similar memories and adult hippocampal 
neurogenesis (ahNG) has been associated with improved performance in pattern separation behavioral tasks (Aimone et al., 2009; Sahay et al., 2011). In several studies a reduction in newborn cells was found to correlate with specific cognitive deficits, and in particular with spatial memory impairment (Shors et al., 2001; Aimone et al., 2006; Denis-Donini et al., 2008; Deng et al., 2010; Couillard-Despres et al., 2011; Aimone et al., 2014). Context-dependent memory, and specifically performance in contextual fear conditioning tasks, was also found to be neurogenesis-dependent (Gonçalves et al., 2016).

A vast array of research investigated factors that regulate ahNG. External stimuli, including learning, environmental enrichment, and exercise have profound effects on proliferation/ differentiation of NPC as well as survival of their progeny (van Praag et al., 2005; Garthe et al., 2016). Aging, chronic stress and social isolation result in negative impact on ahNG (Schoenfeld and Gould, 2012; Seib and Martin-Villalba, 2015; Famitafreshi et al., 2016) and reduction of hippocampal neurogenesis has been hypothesized to contribute to cognitive decline or mood alterations associated with those conditions (Aimone et al., 2014).

Extensive research efforts suggest that ahNG may be deregulated in several neuropsychiatric disorders, including major depressive disorder (Kempermann and Kronenberg, 2003; Mirescu and Gould, 2006; Denis-Donini et al., 2008; Kempermann et al., 2008; Yun et al., 2016).

An intringuing aspect of ahNG is its susceptibility to pharmacological modulation (Duman et al., 2001; Dranovsky and Hen, 2006; Xu et al., 2006; Zhao et al., 2008; Bortolotto et al., 2014). Antidepressants increase hippocampal neurogenesis (Malberg, 2004). Interestingly, such increase requires several weeks and occurs in parallel with the onset of the antidepressant effects (Mendez-David et al., 2013). A vast array of experimental studies demonstrated that antidepressants counteract stressreduced ahNG in rodent models of depressive-like disorder (Pittenger and Duman, 2008; Eisch and Petrik, 2012). An increased number of hippocampal NPC was reported in postmortem brain of depressed patients who were treated with antidepressants (Boldrini et al., 2009, 2012, 2014). Although still controversial, it has been suggested that antidepressants require ahNG to exert some behavioral effects in rodents (Santarelli et al., 2003; David et al., 2009) and that ahNG may contribute to the antidepressant activity of these drugs in the clinical setting (Jun et al., 2012). In line with this hypothesis, preclinical studies evaluating effects on ahNG have become part of the discovery process of recently approved antidepressant drugs (Soumier et al., 2009; Guilloux et al., 2013) or of clinically relevant drugs which, in addition to their approved indications, may potentially exert antidepressant activity (Valente et al., 2012; Cuccurazzu et al., 2013).

\section{OPIATES AS NEGATIVE MODULATORS OF ahNG}

Emerging evidence suggest that several psychoactive drugs result in molecular changes that may negatively affect different aspects of ahNG (Eisch et al., 2000; Yamaguchi et al., 2004). These findings have important clinical implications since they raise the possibility that cognitive dysfunction and/or mood alteration in the setting of such drug use and/or abuse may, at least in part, be related to alterations in ahNG (Yun et al., 2016).

Opiate drugs are powerful analgesics which are also among the most commonly abused addictive drugs. Clinical research suggested the occurrence of deficits in memory tasks, attention, verbal fluency and general cognitive performance in opiate addicts (Cipolli and Galliani, 1987; Guerra et al., 1987; Gruber et al., 2007). Controversial, but of potential clinical relevance, is the possibility that cognitive impairment may also occur in non-addicted patients subjected to chronic opiate treatment (Sjøgren et al., 2005; Gaertner et al., 2006; Kendall et al., 2010; Kurita et al., 2011; Højsted et al., 2012). Despite opiate effects on cognition are difficult to decipher due to their central depressant effects, preclinical research supports the idea that chronic administration of opiates may interfere with cognition independently of performance (Spain and Newsom, 1991; Miladi Gorji et al., 2008). As an example, in rats, chronic morphine administration impaired hippocampal dependent long-term memory retention. Moreover, a selective impairment in spatial memory, which is considered to be neurogenesis-dependent, was observed in morphine-compared to vehicle-treated animals (Miladi Gorji et al., 2008).

Depression often co-occurs with chronic pain and an emerging line of inquiry is also the association between opiate use and the risk of depression (Scherrer et al., 2014, 2015, 2016; Smith et al., 2015). In particular, the onset of a new depressive state has been associated with longer drug administration (Scherrer et al., 2016).

Altogether several experimental data suggest that long-term opiate may produce maladaptive changes in brain structures involved in cognition and mood regulation such as the hippocampus. In morphine-dependent animals, mechanisms responsible for the disruption of long-term memory retention have been suggested, including effects on dendritic spine stability (Liao et al., 2005) and long-term potentiation (Nugent et al., 2007). ahNG is among the forms of neural plasticity which are regulated by opiates (Zhang et al., 2016a). Actually, opiates were the first drugs shown to negatively impact hippocampal neurogenesis (Eisch et al., 2000). Since then, numerous rodent studies confirmed that finding (Mandyam et al., 2004; Kahn et al., 2005; Eisch and Harburg, 2006; Arguello et al., 2008; Zhang et al., 2016b). Based on these reports, it can be hypothesized that opiates may produce long-lasting effects on the neuronal circuitry involved in mood and cognition through, at least in part, disruption of ahNG.

\section{OPIATE EFFECT ON DISTINCT STAGES AND CELL TYPES OF ahNG}

Adult neurogenesis is a complex, multistage process which consists of a series of developmental events, namely proliferation, differentiation, migration, maturation and survival of NSC/NPC and their progeny. Based on their developmental stage, different cells participating in ahNG can be recognized and classified. 
Briefly, radial-glia-like stem cells, which are both glial fibrillary acidic protein (GFAP) and nestin positive are defined as Type-1 cells; Type- 2 cells are neural progenitors which are highly proliferative and nestin ${ }^{+} / \mathrm{GFAP}^{-}$; neuroblasts which express doublecortin and the polysialylated form of neural cell adhesion molecule (PSA-NCAM) are referred to as Type-3 cells.

Over the last few years, extensive progress has been made on how morphine can disrupt neurogenesis in the adult rodent hippocampus (Zhang et al., 2016a). The first report correlating opiate administration and adult neurogenesis was by the group of Amelia Eisch that, in 2000, reported that chronic morphine, administered via a subcutaneous pellet, decreased the number of cells which incorporated the thymidine analog BromodeoxyUridine (BrdU) in rodent SGZ. Importantly, no effect of acute morphine administration was reported (Eisch et al., 2000). Since then, extensive evidence has been accumulated on the negative impact of morphine on NSC/NPC proliferation, using BrdU or endogenous markers of cell proliferation/cell cycle (Mandyam et al., 2004; Kahn et al., 2005; Arguello et al., 2008). Morphine effects appeared to be independent from the route of administration (subcutaneous pellet vs. intraperitoneal injection) and to occur during settings of both forced and selfadministration (Mandyam et al., 2004; Kahn et al., 2005; Fischer et al., 2008).

Survival of newborn cells is also reduced by morphine. After being born in the dentate gyrus, a large portion of newly generated cells die within a few days (Dayer et al., 2003). Chronic morphine treatment decreased granule cell survival in vivo, by largely reducing the number of 4 -week-old BrdUlabeled cells in the dentate gyrus of drug-treated compared to control rats (Eisch et al., 2000). Although adult hippocampal NPC can be isolated and maintained in culture with self renewal and multipotential properties (Valente et al., 2012; Cuccurazzu et al., 2013), surprisingly few studies investigated the effects of opiates in vitro. In one report morphine exposure in cultured NSC/NPCs resulted not only in reduced proliferation but also in an increased caspase- 3 activity in nestin $^{+} / \mathrm{GFAP}^{+}$cells and not in neuroblasts (Willner et al., 2014).

The detailed mechanisms of regulation of ahNG by morphine remain to be fully clarified. There is evidence of morphine acting directly on neural progenitors by engagement of opioid receptors on their cell surface, but also indirectly. Opiate analgesics exert their effects through receptor subtypes, referred to MOR, KOR and DOR, which interact with endogenous opioid peptides. The contribution of different receptor subtypes to the negative effects on ahNG has been investigated by both genetic and pharmacological approaches, pointing to a major role of MOR. We demonstrated that morphine adversely impacted on neuronal differentiation, neurite outgrowth and survival of adult hippocampal NPC and their progeny (Meneghini et al., 2014). MOR pharmacological blockade confirmed that the receptor subtype was responsible for morphine effects (Meneghini et al., 2014). Interestingly, knock-out of MOR enhanced adult-born granule cell survival in vivo, suggesting that endogenous opioids may have a negative effect on ahNG
(Harburg et al., 2007). These findings are not consistently confirmed in vitro. In isolated rat hippocampal NPC, incubation with $\beta$-endorphin increased total DNA content and the number of cells expressing proliferation markers such as Proliferating Cell Nuclear Antigen (PCNA) and phosphorylated histone H3 (pHisH3), and these effects were antagonized by naloxone (Persson et al., 2003a). The same research group reported that MOR and DOR antagonists decrease proliferation of cultured NPC (Persson et al., 2003b). Similarly, the long acting opioid antagonist naltrexone was shown to reduce cell proliferation in the hippocampus of adult rats (Holmes and Galea, 2002).

Opiates also interfere with NPC fate specification. Type-3 cell number was diminished by chronic morphine (Kahn et al., 2005). Moreover, in rat, repeated morphine treatment altered the GABAergic phenotype of adult-born hippocampal granule cells by increasing the GABA synthesizing enzyme glutamate decarboxylase-67 (Kahn et al., 2005). A more detailed analysis using BrdU and Ki67 proliferation markers concluded that morphine treatment increased Type- $2 \mathrm{~b}$ and decreased Type3 cells in mouse SGZ (Arguello et al., 2008). Also in vitro a remarkable decrease in neuronal differentiation of mouse hippocampal NPC by morphine has been demonstrated, an effect which is MOR mediated (Meneghini et al., 2014; Willner et al., 2014). Chronic treatment with MOR and DOR antagonists decreased adult NSC/NPC differentiation into astrocytes and oligodendrocytes, while favoring their neuronal differentiation. In the same experimental setting KOR antagonists had no effect (Persson et al., 2003b). It cannot be excluded that opiates may also affect astrocytes (that express opioid receptors) which, in turn, can modulate ahNG with different mechanisms, including via secreted molecules (Cvijetic et al., 2017). Immature adult generated neurons are excited by GABA (Ge et al., 2006) and they need excitatory signals from the preexisting circuit to complete their differentiation and maturation. Opiate agonists may interfere with this process by decreasing GABA release (Neumaier et al., 1988). Studies are needed to further understand the role of endogenous opioids and receptors in ahNG homeostasis (Lutz and Kieffer, 2013).

The intracellular signaling pathways involved in the negative effects of morphine on neural progenitors were investigated only in a few studies. The basic helix-loop-helix transcription factor NeuroD1 is negatively regulated by morphine in NPC cultures (Zheng et al., 2010). Under the conditioned place preference paradigm morphine, through a mechanism involving NeuroD1, impaired the differentiation of NSC/NPC into immature neurons (Zhang et al., 2016b). Xu et al. (2015) demonstrated that, in presence of morphine, mouse NPC preferentially differentiated into astrocytes and not neurons. This effect was mediated by MOR and by miR181a/Prox1/Notch1 pathway activation. Interestingly, the same group also demonstrated that miR-181a/Prox1/Notch1 pathway regulates NPC differentiation in a ligand-dependent manner (Xu et al., 2015), pointing to differences in the effect of distinct opiate molecules on mouse NPC differentiation. Morphine modulates the lineage-specific differentiation of NPC by PKCE-dependent 
ERK activation with subsequent TAR RNA-binding protein (TRBP, a cofactor of Dicer) phosphorylation and miR-181a maturation. Conversely fentanyl activated ERK via the $\beta$-arrestindependent pathway, followed by nuclear translocation of phosphoERK.

Overall, available data support the idea that morphine negatively affects neurogenesis acting on multiple cellular types and stages of the neuroplasticity process. Morphine properties on neurogenesis are also shared by other opiates. The partial agonist buprenorphine, when administered via subcutaneous injections over a 3-day period, reduced the number of actively proliferating cells in the hippocampus of adult mice (Pettit et al., 2012). On the other hand, differences in the signaling pathways activated in NPC by different opiate drugs may underlie potential differences in their impact on ahNG.

In the future studies, should be specifically designed to correlate more stringently the disruptive cognitive effects of distinct opiates with specific alterations in ahNG and to discriminate those that are strictly dependent on neurogenesis from the ones that are neurogenesis-independent.

\section{NOT ALL OPIATES ARE CREATED EQUAL: DIFFERENT IMPACT ON HIPPOCAMPAL NEUROGENESIS OF DISTINCT DRUGS}

A recent in vivo study in rat found that chronically administered methadone does not alter parameters relevant to ahNG including the number of Ki67-, doublecortin-, or BrdUimmunoreactive cells (Sankararaman et al., 2012). These results suggest that, unlike morphine, methadone may not alter hippocampal plasticity. Interestingly methadone is an atypical opiate, since it is a MOR agonist and a non-competitive NMDA antagonist (Gorman et al., 1997). Incidentally, NMDA antagonists positively modulate hippocampal neurogenesis in rodents (Nacher et al., 2001; Maekawa et al., 2009). Future investigation should address whether the lack of negative effects on ahNG by methadone could be ascribed to its NMDA receptor antagonism.

Tapentadol is a centrally acting analgesic drug which combines, in a single molecule, MOR agonism and blockade of norepinephrine (NE) reuptake (Tzschentke et al., 2007). Since ahNG is positively modulated by NE (Jha et al., 2006; Kulkarni and Dhir, 2007), we compared the effects of morphine and tapentadol on differentiation, maturation and survival of neurons generated from adult hippocampal NPC in vitro. Morphine significantly hampered neuronal differentiation, neurite outgrowth and survival of adult NPC and their progeny (Meneghini et al., 2014). In presence of tapentadol cell survival was not affected. Conversely, tapentadol reduced the number of newly generated neurons and their neurite outgrowth but only at concentrations which activate MOR and not at higher ones which block NE reuptake. Specifically, tapentadol proneurogenic and antiapoptotic effects appeared to be mediated by activation of $\beta 2$ and $\alpha 2$ adrenergic receptors, respectively (Meneghini et al., 2014). As a proof of concept, in the same experimental model, morphine antineurogenic and proapoptotic effects were counteracted by reboxetine, an antidepressant which selectively blocks noradrenaline reuptake (Meneghini et al., 2014). In line with these in vitro results, chronic administration of a clinically relevant dose of tapentadol did not negatively affect proliferation and differentiation toward the neuronal lineage of newly generated cells in adult mouse hippocampus (Meneghini et al., 2014). Altogether these data support the idea that the noradrenergic component in tapentadol has the potential to counteract the adverse MORmediated effects on hippocampal neurogenesis both in vitro and in vivo. In principle, this counter-balancing effect may result, like for the atypical opiate methadone, in less or no dysfunction in adult neurogenesis and, potentially, in neurogenesis-associated functions after long-term treatment in vivo.

\section{CLINICAL IMPLICATIONS AND LONG-TERM PERSPECTIVES}

Cognitive dysfunction has been often reported in opiate drug abusers (Eisch and Harburg, 2006; Canales, 2007). Moreover, major depression represents an important comorbidity in chronic pain states and recent work has suggested an association between prolonged opiate use and the risk of new onset depression (Scherrer et al., 2015, 2016).

Preclinical evidence summarized in this review support the idea that disruption of ahNG may, at least in part, contribute to the long-lasting effects produced by some opiates, like morphine, on cognition and mood regulation. Although preliminary, these preclinical data mark the importance of taking into account inhibition of ahNG as a potential longterm consequence of opiate use also in the clinical setting. This aspect appears even more relevant in consideration of the fact that chronic pain per se may induce profound changes in hippocampal plasticity, including deregulated hippocampal neurogenesis (Mutso et al., 2012; Dellarole et al., 2014).

While we wait for a definitive answer on any causal correlation between long term-opiate treatment and cognitive and emotional impairment in chronic pain patients, preclinical studies should be undertaken to increase our current understanding of the cellular and molecular effects of opiates on adult NPC and their progeny. Moreover, experimental work should be aimed at understanding differences between distinct opiates in their potential for disrupting ahNG. Ultimately these studies may help us to unravel different level of risk associated with distinct treatment options. In principle, drugs like methadone and tapentadol may result, after drug long-term treatment, in reduced or absent dysfunction in ahNG compared to morphine and other opiates. Alternatively, other analgesic drugs which do not reduce but rather increase ahNG in preclinical models like pregabalin/gabapentin (Valente et al., 2012) and acetyl-Lcarnitine (Cuccurazzu et al., 2013) could be proposed, at least in neuropathic pain where they are effective. A better understanding 
of whether different opiate molecules affect molecular and cellular aspects of ahNG may also help designing and developing novel analgesic drugs for chronic pain states. Several drugs acting at different targets are under development for chronic pain treatment (Sasikumar et al., 2010; Bennett et al., 2012; Chang et al., 2015; Yaksh et al., 2015). We propose that future drug design should take into consideration the development of powerful analgesics that, by preserving ahNG, may also protect cognitive functions and counteract mood alterations which often represent comorbidities in chronic pain states.

\section{REFERENCES}

Aimone, J. B., Li, Y., Lee, S. W., Clemenson, G. D., Deng, W., and Gage, H. (2014). Regulation and function of adult neurogenesis: from genes to cognition. Physiol. Rev. 94, 991-1026. doi: 10.1152/physrev.00004.2014

Aimone, J. B., Wiles, J., and Gage, F. H. (2006). Potential role for adult neurogenesis in the encoding of time in new memories. Nat. Neurosci. 9, 723-727. doi: $10.1038 / \mathrm{nn} 1707$

Aimone, J. B., Wiles, J., and Gage, F. H. (2009). Computational influence of adult neurogenesis on memory encoding. Neuron 61, 187-202. doi: 10.1016/j.neuron. 2008.11.026

Arguello, A. A., Harburg, G. C., Schonborn, J. R., Mandyam, C. D., Yamaguchi, M., and Eisch, A. J. (2008). Time course of morphine's effects on adult hippocampal subgranular zone reveals preferential inhibition of cells in S phase of the cell cycle and a subpopulation of immature neurons. Neuroscience 157, 70-79. doi: 10.1016/j.neuroscience.2008.08.064

Bennett, C. E., Burnett, D. A., Greenlee, W. J., Knutson, C. E., Korakas, P., Li, C., et al. (2012). Fused tricyclic mGluR1 antagonists for the treatment of neuropathic pain. Bioorg. Med. Chem. Lett. 22, 1575-1578. doi: 10.1016/j.bmcl. 2011.12.131

Bergmann, O., Spalding, K. L., and Frisén, J. (2015). Adult neurogenesis in humans. Cold. Spring Harb. Perspect. Biol. 7:a018994. doi: 10.1101/cshperspect.a018994

Boldrini, M., Butt, T. H., Santiago, A. N., Tamir, H., Dwork, A. J., Rosoklija, G. B., et al. (2014). Benzodiazepines and the potential trophic effect of antidepressants on dentate gyrus cells in mood disorders. Int. J. Neuropsychopharmacol. 17, 1923-1933. doi: 10.1017/S1461145714000844

Boldrini, M., Hen, R., Underwood, M. D., Rosoklija, G. B., Dwork, A. J., Mann, J. J., et al. (2012). Hippocampal angiogenesis and progenitor cell proliferation are increased with antidepressant use in major depression. Biol. Psychiatry. 72, 562-571. doi: 10.1016/j.biopsych.2012.04.024

Boldrini, M., Underwood, M. D., Hen, R., Rosoklija, G. B., Dwork, A. J., JohnMann, J., et al. (2009). Antidepressants increase neural progenitor cells in the human hippocampus. Neuropsychopharmacology 34, 2376-2389. doi: 10.1038/ npp. 2009.75

Bonaguidi, M. A., Song, J., Ming, G. L., and Song, H. (2012). A unifying hypothesis on mammalian neural stem cell properties in the adult hippocampus. Curr. Opin. Neurobiol. 22, 754-761. doi: 10.1016/j.conb.2012.03.013

Bortolotto, V., Cuccurazzu, B., Canonico, P. L., and Grilli, M. (2014). $\mathrm{NF}-\kappa \mathrm{B}$ mediated regulation of adult hippocampal neurogenesis: relevance to mood disorders and antidepressant activity. Biomed. Res. Int. 2014:612798. doi: $10.1155 / 2014 / 612798$

Canales, J. J. (2007). Adult neurogenesis and the memories of drug addiction. Eur. Arch. Psychiatry Clin. Neurosci. 257, 261-270. doi: 10.1007/s00406-007-0730-6

Chang, D. S., Raghavan, R., Christiansen, S., and Cohen, S. P. (2015). Emerging targets in treating pain. Curr. Opin. Anaesthesiol. 28, 379-397. doi: 10.1097/ ACO.0000000000000216

Cipolli, C., and Galliani, I. (1987). Addiction time and intellectual impairment in heroin users. Psychol. Rep. 60, 1099-1105. doi: 10.2466/pr0.1987.60.3c.1099

Couillard-Despres, S., Iglseder, B., and Aigner, L. (2011). Neurogenesis, a cellular plasticity and cognition: the impact of stem cells in the adult and aging brain. Gerontology 57, 559-564. doi: 10.1159/000323481

Cuccurazzu, B., Bortolotto, V., Valente, M. M., Ubezio, F., Koverech, A., Canonico, P. L., et al. (2013). Upregulation of $m$ Glu2 receptors via $N F-\kappa B$ p 65 acetylation is

\section{ACKNOWLEDGMENT}

We would like to apologize for excellent work that could not be quoted in this review for space limitations.

\section{AUTHOR CONTRIBUTIONS}

$\mathrm{VB}$ and MG were involved in the concept, literature screening, and writing of the article, and approved it for publication.

involved in the Proneurogenic and antidepressant effects of acetyl-L-carnitine. Neuropsychopharmacology 38, 2220-2230. doi: 10.1038/npp.2013.121

Cvijetic, S., Bortolotto, V., Manfredi, M., Ranzato, E., Marengo, E., Salem, R., et al. (2017). Cell autonomous and noncell-autonomous role of NF-кB p50 in astrocyte-mediated fate specification of adult neural progenitor cells. Glia 65, 169-181. doi: 10.1002/glia.23085

David, D. J., Samuels, B. A., Rainer, Q., Wang, J. W., Marsteller, D., Mendez, I., et al. (2009). Neurogenesis-dependent and -independent effects of fluoxetine in an animal model of anxiety/depression. Neuron 62, 479-493. doi: 10.1016/j. neruon.2009.04.017

Dayer, A. G., Ford, A. A., Cleaver, K. M., Yassaee, M., and Cameron, H. A. (2003). Short-term and long-term survival of new neurons in the rat dentate gyrus. J. Comp. Neurol. 460, 563-572. doi: 10.1002/cne.10675

Dellarole, A., Morton, P., Brambilla, R., Walters, W., Summers, S., Bernardes, D., et al. (2014). Neuropathic pain- induced depressive like behavior and hippocampal neurogenesis and plasticity are dependent on TNFR1 signalling. Brain Behav. Immun. 41, 65-81. doi: 10.1016/j.bbi.2014.04.003

Deng, W., Aimone, J. B., and Gage, F. H. (2010). New neurons and new memories: how does adult hippocampal neurogenesis affect learning and memory? Nat. Rev. Neurosci. 11, 339-350. doi: 10.1038/nm2822

Denis-Donini, S., Dellarole, A., Crociara, P., Francese, M. T., Bortolotto, V., Quadrato, G., et al. (2008). Impaired adult neurogenesis associated with short-term memory defects in NF-kappaB p50-deficient mice. J. Neurosci. 28, 3911-3919. doi: 10.1523/JNEUROSCI.0148-08.2008

Dranovsky, A., and Hen, R. (2006). Hippocampal neurogenesis: regulation by stress and antidepressants. Biol. Psychiatry 59, 1136-1143. doi: 10.1016/j.biopsych. 2006.03.082

Duman, R. S., Nakagawa, S., and Malberg, J. (2001). Regulation of adult neurogenesis by antidepressant treatment. Neuropsychopharmacology 25, 836-844. doi: 10.1016/S0893-133X(01)00358-X

Eisch, A. J., Barrot, M., Schad, C. A., Self, D. W., and Nestler, E. J. (2000). Opiates inhibit neurogenesis in the adult rat hippocampus. Proc. Natl. Acad. Sci. U.S.A. 97, 7579-7584. doi: 10.1073/pnas.120552597

Eisch, A. J., and Harburg, G. C. (2006). Opiates, psychostimulants, and adult hippocampal neurogenesis: insights for addiction and stem cell biology. Hippocampus 16, 271-286. doi: 10.1002/hipo.20161

Eisch, A. J., and Petrik, D. (2012). Depression and hippocampal neurogenesis: a road to remission? Science 338, 72-75. doi: 10.1126/science.1222941

Famitafreshi, H., Karimian, M., and Fatima, S. (2016). Synergistic effects of social isolation and morphine addiction on reduced neurogenesis and BDNF levels and the resultant deficits in cognition and emotional state in male rats. Curr. Mol. Pharmacol. 9, 337-347. doi: 10.2174/1874467209666160822102153

Fischer, S. J., Arguello, A. A., Charlton, J. J., Fuller, D. C., Zachariou, V., and Eisch, A. J. (2008). Morphine blood levels, dependence, and regulation of hippocampal subgranular zone proliferation rely on administration paradigm. Neuroscience 151, 1217-1224. doi: 10.1016/j.neuroscience.2007.11.035

Gaertner, J., Radbruch, L., Giesecke, T., Gebershagen, H., Petzke, F., Ostgathe, C., et al. (2006). Assessing cognition and psychomotor function under long-term treatment with controlled release oxycodone in non cancer patients. Acta Anaesthesiol. Scand. 50, 664-672. doi: 10.1111/j.1399-6576.2006.01027.x

Garthe, A., Roeder, I., and Kempermann, G. (2016). Mice in an enriched environment learn more flexibly because of adult hippocampal neurogenesis. Hippocampus 26, 261-271. doi: 10.1002/hipo.22520 
Ge, S., Goh, E. L. K., Sailor, K. A., Kitabatake, Y., Ming, G. L., and Song, H. (2006). GABA regulates synaptic integration of newly generated neurons in the adult brain. Nature 439, 589-593. doi: 10.1038/nature04404

Gonçalves, J. T., Schafer, S. T., and Gage, F. H. (2016). Adult neurogenesis in the hippocampus: from stem cells to behavior. Cell 67, 897-914. doi: 10.1016/j.cell. 2016.10.021

Gorman, A. L., Elliott, K. J., and Inturrisi, C. E. (1997). The d- and l-isomers of methadone bind to the non-competitive site on the N-methyl-D-aspartate (NMDA) receptor in rat forebrain and spinal cord. Neurosci. Lett. 223, 5-8. doi: 10.1016/S0304-3940(97)13391-2

Gruber, S. A., Silveri, M. M., and Yurgelun-Todd, D. A. (2007). Neuropsychological consequences of opiate use. Neuropsychol. Rev. 17, 299-315. doi: 10.1007/ s11065-007-9041-y

Guerra, D., Solé, A., Camí, J., and Tobeña, A. (1987). Neuropsychological performance in opiate addicts after rapid detoxification. Drug Alcohol Depend. $20,261-270$

Guilloux, J. P., Mendez-David, I., Pehrson, A., Guiard, B. P., Repérant, C., Orvoën, S., et al. (2013). Antidepressant and anxiolytic potential of the multimodal antidepressant vortioxetine (Lu AA21004) assessed by behavioural and neurogenesis outcomes in mice. Neuropharmacology 73, 147-159. doi: 10.1016/j.neuropharm.2013.05.014

Harburg, G. C., Hall, F. S., Harrist, A. V., Sora, I., Uhl, G. R., and Eisch, A. J. (2007). Knockout of the mu opioid receptor enhances the survival of adult-generated hippocampal granule cell neurons. Neuroscience 144, 77-87. doi: 10.1016/j.neuroscience.2006.09.018

Højsted, J., Kurita, G. P., Kendall, S., Lundorff, L., De-Mattos-Pimenta, C. A., and Sjøgren, P. (2012). Non-analgesic effects of opioids: the cognitive effects of opioids in chronic pain of malignant and non-malignant origin. An Update. Curr. Pharm. Des. 18, 6116-6122. doi: 10.2174/13816121803582522

Holmes, M. M., and Galea, L. A. M. (2002). Defensive behavior and hippocampal cell proliferation: differential modulation by naltrexone during stress. Behav. Neurosci. 116, 160-168. doi: 10.1037/0735-7044.116.1.160

Jha, S., Rajendran, R., Davda, J., and Vaidya, V. A. (2006). Selective serotonin depletion does not regulate hippocampal neurogenesis in the adult rat brain: differential effects of p-chlorophenylalanine and 5,7-dihydroxytryptamine. Brain Res. 1075, 48-59. doi: 10.1016/j.brainres.2005.12.110

Jun, H., Mohammed-Qasim-Hussaini, S., Rigby, M. J., and Jang, M. H. (2012). Functional role of adult hippocampal neurogenesis as a therapeutic strategy for mental disorders. Neural Plast. 2012:854285. doi: 10.1155/2012/854285

Kahn, L., Alonso, G., Normand, E., and Manzoni, O. J. (2005). Repeated morphine treatment alters polysialylated neural cell adhesion molecule, glutamate decarboxylase-67 expression and cell proliferation in the adult rat hippocampus. Eur. J. Neurosci. 21, 493-500. doi: 10.1111/j.1460-9568.2005. 03883.x

Kempermann, G., Gast, D., Kronenberg, G., Yamaguchi, M., and Gage, F. H. (2003). Early determination and long-term persistence of adult-generated new neurons in the hippocampus of mice. Development 130, 391-399. doi: 10.1242/dev. 00203

Kempermann, G., Jessberger, S., Steiner, B., and Kronenberg, G. (2004). Milestones of neuronal development in the adult hippocampus. Trends Neurosci. 27, 447-452. doi: 10.1016/j.tins.2004.05.013

Kempermann, G., Krebs, J., and Fabel, K. (2008). The contribution of failing adult hippocampal neurogenesis to psychiatric disorders. Curr. Opin. Psychiatry 21, 290-295. doi: 10.1097/YCO.0b013e3282fad375

Kempermann, G., and Kronenberg, G. (2003). Depressed new neuronsadult hippocampal neurogenesis and a cellular plasticity hypothesis of major depression. Biol. Psychiatry 54, 499-503. doi: 10.1016/S0006-3223(03) 00319-6

Kendall, S. E., Sjøgren, P., Pimenta, C. A., Højsted, J., and Kurita, G. P. (2010). The cognitive effects of opioids in chronic non-cancer pain. Pain 150, 225-230. doi: $10.1016 /$ j.pain.2010.05.012

Kulkarni, S. K., and Dhir, A. (2007). Effect of various classes of antidepressants in behavioral paradigms of despair. Prog. Neuropsychopharmacol. Biol. Psychiatry 31, 1248-1254. doi: 10.1016/j.pnpbp.2007.05.002

Kurita, G. P., Sjøgren, P., Ekholm, O., Kaasa, S., Loge, J. H., Poviloniene, I., et al. (2011). Prevalence and predictors of cognitive dysfunction in opioid-treated patients with cancer: a multinational study. J. Clin. Oncol. 29, 1297-1303. doi: 10.1200/JCO.2010.32.6884
Liao, D., Lin, H., Ping, Y. L., and Loh, H. H. (2005). Mu-opioid receptors modulate the stability of dendritic spines. Proc. Natl. Acad. Sci. U.S.A. 102, 1725-1730. doi: $10.1073 /$ pnas. 0406797

Lutz, P. E., and Kieffer, B. L. (2013). The multiple facets of opioid receptor function: implications for addiction. Curr. Opin. Neurobiol. 23, 473-479. doi: 10.1016/j. conb.2013.02.005

Maekawa, M., Namba, T., Suzuki, E., Yuasa, S., Kohsaka, S., and Uchino, S. (2009). NMDA receptor antagonist memantine promotes cell proliferation and production of mature granule neurons in the adult hippocampus. Neurosci. Res. 63, 259-266. doi: 10.1026/j.neures.2008.12.006

Malberg, J. E. (2004). Implications of adult hippocampal neurogenesis in antidepressant action. J. Psychiatry Neurosci. 29, 196-205.

Mandyam, C. D., Norris, R. D., and Eisch, A. J. (2004). Chronic morphine induces premature mitosis of proliferating cells in the adult mouse subgranular zone. J. Neurosci. Res. 76, 783-794. doi: 10.1002/jnr.20090

Mendez-David, I., Hen, R., Gardier, A. M., and David, D. J. (2013). Adult hippocampal neurogenesis: an actor in the antidepressant-like action. Ann. Pharm. Fr. 71, 143-149. doi: 10.1016/j.pharma.2013.02.006

Meneghini, V., Cuccurazzu, B., Bortolotto, V., Ramazzotti, V., Ubezio, F., Tzschentke, T. M., et al. (2014). The noradrenergic component in tapentadol action counteracts $\mu$-opioid receptor-mediated adverse effects on adult neurogenesis. Mol. Pharmacol. 85, 658-670. doi: 10.1124/mol.113.091520

Miladi Gorji, H., Rashidy-Pour, A., and Fathollahi, Y. (2008). Effects of morphine dependence on the performance of rats in reference and working versions of the water maze. Physiol. Behav. 93, 622-627. doi: 10.1016/j.physbeh.2007.11.002

Mirescu, C., and Gould, E. (2006). Stress and adult neurogenesis. Hippocampus 16, 233-238. doi: 10.1002/hipo.20155

Mutso, A. A., Radzicki, D., Baliki, M. N., Huang, L., Banisadr, G., Centeno, M. V., et al. (2012). Abnormalities in hippocampal functioning with persistent pain. J. Neurosci. 25, 5747-5756. doi: 10.1523/JNEUROSCI.0587-12.2012

Nacher, J., Rosell, D. R., Alonso-Llosa, G., and McEwen, B. S. (2001). NMDA receptor antagonist treatment induces a long-lasting increase in the number of proliferating cells, PSA-NCAM-immunoreactive granule neurons and radial glia in the adult rat dentate gyrus. Eur. J. Neurosci. 13, 512-520. doi: 10.1046/j. 0953-816x.2000.01424.x

Neumaier, J. F., Mailheau, S., and Chavkin, C. (1988). Opioid receptor-mediated responses in the dentate gyrus and CAl region of the rat hippocampus. J. Pharmacol. Exp. Ther. 244, 564-570.

Nugent, F. S., Penick, E. C., and Kauer, J. A. (2007). Opioids block long-term potentiation of inhibitory synapses. Nature 446, 1086-1090. doi: 10.1038/ nature 05726

Persson, A. I., Thorlin, T., Bull, C., and Eriksson, P. S. (2003a). Opioid-induced proliferation through the MAPK pathway in cultures of adult hippocampal progenitors. Mol. Cell. Neurosci. 23, 360-372. doi: 10.1016/S1044-7431(03) 00061-7

Persson, A. I., Thorlin, T., Bull, C., Zarnegar, P., Ekman, R., Terenius, L., et al. (2003b). Mu- and delta-opioid receptor antagonists decrease proliferation and increase neurogenesis in cultures of rat adult hippocampal progenitors. Eur. J. Neurosci. 17, 1159-1172. doi: 10.1046/j.1460-9568.2003.02538.x

Pettit, A. S., DesRoches, R., and Bennett, S. A. L. (2012). The opiate analgesic buprenorphine decreases proliferation of adult hippocampal neuroblasts and increases survival of their progeny. Neuroscience 200, 211-222. doi: 10.1016/j. neuroscience.2011.10.039

Pittenger, C., and Duman, R. S. (2008). Stress, depression, and neuroplasticity: a convergence of mechanisms. Neuropsychopharmacology 33, 88-109. doi: 10.1038/sj.npp.1301574

Sahay, A., Wilson, D. A., and Hen, R. (2011). Pattern separation: a common function for new neurons in hippocampus and olfactory bulb. Neuron 70, 582-588. doi: 10.1016/j.neuron.2011.05.012

Sankararaman, A., Masiulis, I., Richardson, D. R., Andersen, J. M., Mørland, J., and Eisch, A. J. (2012). Methadone does not alter key parameters of adult hippocampal neurogenesis in the heroin-naïve rat. Neurosci. Lett. 516, 99-104. doi: 10.1016/j.neulet.2012.03.066

Santarelli, L., Saxe, M., Gross, C., Surget, A., Battaglia, F., Dulawa, S., et al. (2003). Requirement of hippocampal neurogenesis for the behavioral effects of antidepressants. Science 301, 805-809. doi: 10.1126/science.1083328

Sasikumar, T. K., Qiang, L., Burnett, D., Greenlee, W. J., Li, C., Grilli, M., et al. (2010). A-ring modifications on the triazafluorenone core structure and 
their mGluR1 antagonist properties. Bioorg. Med. Chem. Lett. 20, 2474-2477. doi: 10.1016/j.bmcl.2010.03.004

Scherrer, J. F., Salas, J., Copeland, L. A., Stock, E. M., Schneider, F. D., Sullivan, M., et al. (2016). Increased risk of depression recurrence after initiation of prescription opioids in noncancer pain patients. J. Pain 17, 473-482. doi: 10.1016/j.jpain.2015.12.012

Scherrer, J. F., Salas, J., Lustman, P. J., Burge, S., and Schneider, F. D. (2015). Residency research network of texas (RRNeT) investigators. Change in opioid dose and change in depression in a longitudinal primary care patient cohort. Pain 156, 348-355. doi: 10.1097/01.j.pain.0000460316.58110.a0

Scherrer, J. F., Svrakic, D. M., Freedland, K. E., Chrusciel, T., Balasubramanian, S., Bucholz, K. K., et al. (2014). Prescription opioid analgesics increase the risk of depression. J. Gen. Intern. Med. 29, 491-499. doi: 10.1007/s11606-013-2648-1

Schoenfeld, T. J., and Gould, E. (2012). Stress, stress hormones, and adult neurogenesis. Exp. Neurol. 233, 12-21. doi: 10.1016/j.expneurol.2011.01.008

Seib, D. R., and Martin-Villalba, A. (2015). Neurogenesis in the normal aging hippocampus: a mini-review. Gerontology 61, 327-335. doi: 10.1159/000368575

Seri, B., Garcia-Verdugo, J. M., Collado-Morente, L., McEwen, B. S., and AlvarezBuylla, A. (2004). Cell types, Lineage, and Architecture of the germinal zone in the adult dentate gyrus. J. Comp. Neurol. 478, 359-378. doi: 10.1002/cne.20288

Shors, T. J., Miesagaes, G., Beylin, A., Zhao, M., Rydel, T., and Gould, E. (2001). Neurogenesis in the adult is involved in the formation of trace memories. Nature 410, 372-376. doi: 10.1038/35066584

Sjøgren, P., Christrup, L. L., Petersen, M. A., and Hojsted, J. (2005). Neuropsychological assessment of chronic non malignant pain patients treated in a multidisciplinary centre. Eur. J. Pain 9, 453-462. doi: 10.1016/j.ejpain.2004. 10.005

Smith, K., Mattick, R. P., Bruno, R., Nielsen, S., Cohen, M., Campbell, G., et al. (2015). Factors associated with the development of depression in chronic noncancer pain patients following the onset of opioid treatment for pain. J. Affect. Disord. 184, 72-80. doi: 10.1016/j.jad.2015.05.049

Soumier, A., Banasr, M., Lortet, S., Masmejean, F., Bernard, N., KerkerianLe-Goff, L., et al. (2009). Mechanisms contributing to the phase-dependent regulation of neurogenesis by the novel antidepressant, agomelatine, in the adult rat hippocampus. Neuropsychopharmacology 34, 2390-2403. doi: 10.1038/ npp. 2009.72

Spain, J. W., and Newsom, G. C. (1991). Chronic opioids impair acquisition of both radial maze and Y-maze choice escape. Psychopharmacology (Berl). 105, 101-106. doi: 10.1007/BF02316870

Tzschentke, T. M., Christoph, T., Kögel, B., Schiene, K., Hennies, H. H., Englberger, W., et al. (2007). (-)-(1R,2R)-3-(3-dimethylamino-1-ethyl-2methyl-propyl)-phenol hydrochloride (tapentadol $\mathrm{HCl}$ ): a novel mu-opioid receptor agonist/norepinephrine reuptake inhibitor with broad-spectrum analgesic properties. J. Pharmacol. Exp. Ther. 323, 265-276. doi: 10.1124/jpet. 107.126052

Valente, M. M., Bortolotto, V., Cuccurazzu, B., Ubezio, F., Meneghini, V., Francese, M. T., et al. (2012). $\alpha 2 \delta$ ligands act as positive modulators of adult hippocampal neurogenesis and prevent depression-like behavior induced by chronic restraint stress. Mol. Pharmacol. 82, 271-280. doi: 10.1124/mol.112.077636

van Praag, H., Shubert, T., Zhao, C., and Gage, F. (2005). Exercise enhances learning and hippocampal neurogenesis in aged mice. J. Neurosci. 25, 8680-8685. doi: 10.1523/JNEUROSCI.1731-05.2005
Willner, D., Cohen-Yeshurun, A., Avidan, A., Ozersky, V., Shohami, E., and Leker, R. R. (2014). Short term morphine exposure in vitro alters proliferation and differentiation of neural progenitor cells and promotes apoptosis via $\mathrm{Mu}$ receptors. PLoS ONE 9:e103043. doi: 10.1371/journal.pone.010 3043

Xu, C., Zheng, H., Loh, H. H., and Law, P. Y. (2015). Morphine promotes astrocyte-preferential differentiation of mouse hippocampal progenitor cells via PKCE-dependent ERK activation and TRBP phosphorylation. Stem Cells 33, 2762-2772. doi: 10.1002/stem.2055

Xu, H., Chen, Z., He, J., Haimanot, S., Li, X., Dyck, L., et al. (2006). Synergetic effects of quietiapine and venlafaxine in preventing the chronic restraint stress-induced decrease in cell proliferation and BDNF expression in rat hippocampus. Hippocampus 16, 551-559. doi: 10.1002/hippo.20184

Yaksh, T. L., Woller, S. A., Ramachandra, R., and Sorkin, L. S. (2015). The search of novel analgesics: targets and mechanisms. F1000Prime Rep. 7:56. doi: 10.12703/ P7-56

Yamaguchi, M., Suzuki, T., Seki, T., Namba, T., Juan, R., Arai, H., et al. (2004). Repetitive cocaine administration decreases neurogenesis in adult rat hippocampus. Ann. N. Y. Acad. Sci. 1025, 351-362. doi: 10.1196/annals. 1316.043

Yun, S., Reynolds, R. P., Masiulis, I., and Eisch, A. J. (2016). Re-evaluating the link between neuropsychiatric disorders and dysregulated adult neurogenesis. Nat. Med. 22, 1239-1247. doi: 10.1038/nm.4218

Zhang, Y., Loh, H. H., and Law, P. Y. (2016a). Effect of Opioid on Adult Hippocampal Neurogenesis. ScientificWorldJournal 2016:2601264. doi: $10.1155 / 2016 / 2601264$

Zhang, Y., Xu, C., Zheng, H., Loh, H. H., and Law, P.-Y. (2016b). Morphine modulates adult neurogenesis and contextual memory by impeding the maturation of neural progenitors. PLoS ONE 11:e0153628. doi: 10.1371/journal. pone. 0153628

Zhao, C., Deng, W., and Gage, F. H. (2008). Mechanisms and functional implications of adult neurogenesis. Cell 132, 645-660. doi: 10.1016/j.cell.2008. 01.033

Zheng, H., Zeng, Y., Chu, J., Kam, A. Y., Loh, H. H., and Law, P. Y. (2010). Modulations of NeuroD activity contribute to the differential effects of morphine and fentanyl on dendritic spine stability. J. Neurosci. 30, 8102-8110. doi: 10.1523/JNEUROSCI.6069-09.2010

Conflict of Interest Statement: In the past, MG has received research grants from drug companies manufacturing analgesic drugs, including Angelini S.p.A, Grunenthal GmbH, Pfizer, Sigma Tau.

The other author declares that the research was conducted in the absence of any commercial or financial relationships that could be construed as a potential conflict of interest.

Copyright $\odot 2017$ Bortolotto and Grilli. This is an open-access article distributed under the terms of the Creative Commons Attribution License (CC BY). The use, distribution or reproduction in other forums is permitted, provided the original author(s) or licensor are credited and that the original publication in this journal is cited, in accordance with accepted academic practice. No use, distribution or reproduction is permitted which does not comply with these terms. 